Rabaska

Revue d'ethnologie de l'Amérique française

DUPONT, JEAN-CLAUDE. Le Temps des sucres. Québec, Les

Éditions GID, 2004, 252 p. ISBN 2-922668-52-5

\title{
Yves Bergeron
}

Volume 2, 2004

URI : https://id.erudit.org/iderudit/201665ar

DOI : https://doi.org/10.7202/201665ar

Aller au sommaire du numéro

Éditeur(s)

Société québécoise d'ethnologie

ISSN

1703-7433 (imprimé)

1916-7350 (numérique)

Découvrir la revue

Citer ce compte rendu

Bergeron, Y. (2004). Compte rendu de [DUPONT, JEAN-CLAUDE. Le Temps des sucres. Québec, Les Éditions GID, 2004, 252 p. ISBN 2-922668-52-5]. Rabaska, 2 , 213-215. https://doi.org/10.7202/201665ar d'utilisation que vous pouvez consulter en ligne.

https://apropos.erudit.org/fr/usagers/politique-dutilisation/ 
Dupont, Jean-Claude. Le Temps des sucres. Québec, Les Éditions GID, 2004, 252 p. ISBN 2-922668-52-5.

Voilà un sujet qui, sans être nouveau, méritait un ouvrage de synthèse. La production du sirop et du sucre d'érable demeure certainement un des sujets particuliers de la culture nord-américaine. Rappelons que Jean-Claude Dupont avait déjà publié en 1975, chez Leméac, un ouvrage intitulé Le Sucre $d u$ pays dans la collection « Traditions du geste et de la parole ». Madeleine Ferron avait d'ailleurs accepté de rédiger la préface dans laquelle elle soulignait la contribution de Jean-Claude Dupont à l'inventaire de « notre patrimoine collectif ». L'originalité de cette première publication se révèle à travers les enquêtes ethnographiques qui permettent de reconstituer la trame des gestes et des techniques. À ce travail d'ethnographie des gestes, Dupont introduisait déjà les coutumes et les croyances liées à cette pratique traditionnelle.

À trente années d'intervalle, Jean-Claude Dupont revisite cette tradition toujours vivante. Cette fois, l'auteur élargit la perspective de la recherche. Puisant aux sources écrites des missionnaires et des voyageurs, il réussit à reconstituer une trame historique qui nous conduit de la découverte par les 
Européens du savoir-faire des Amérindiens jusqu'à l'exploitation de cette ressource unique. Dupont nuance cependant l'originalité de cette industrie nord-américaine en rappelant qu'il existe « cent cinquante espèces d'érables dans le monde et que leur principal foyer se situe dans la chaîne de l'Himalaya. On en retrouve également en Chine, en Norvège, en Europe, au Japon, au Canada et aux États-Unis. " Cependant, cette industrie se concentre principalement dans l'Est du Canada et dans le Nord-Est des États-Unis. C'est pourquoi on retrouve au Québec une tradition vivante bien implantée depuis plus de trois siècles.

Après avoir situé l'importance relative de l'érable à sucre dans le monde et en Amérique du Nord, l'auteur nous conduit «à la cabane ». Dans le troisième chapitre, on découvre les différentes techniques d'entaillage, de cueillette et de transport de la sève. On retrouve dans ce chapitre les images traditionnelles que la mémoire collective conserve de ces visites « à la cabane $»$.

Dupont souligne, dans le quatrième chapitre, l'importance économique de cette activité traditionnelle. Si les produits de l'érable ont toujours constitué une source de revenus appréciable pour les agriculteurs, la production de produits de l'érable est devenue une véritable industrie qui comptait en l'an 2000 quelque 10000 producteurs. Depuis 1997, on note que le Québec fournit $70 \%$ de la production mondiale. L'auteur précise d'ailleurs que $75 \%$ de cette production québécoise est vendue aux États-Unis.

Comme il l'avait fait dans Le Sucre du pays, Dupont rappelle que l'on « se transmet de bouche à oreille des croyances, souvent magico-religieuses, que l'on respecte sans trop vouloir se l'avouer. L'on a aussi l'habitude de faire certains gestes en telles circonstances ou à tel moment de l'année. Le temps des sucres est une période où les occasions ne manquent pas d'exercer ces pratiques. " Dupont aborde notamment les mythes et les légendes qui sont liés à cette activité traditionnelle. Ce chapitre constitue certainement la contribution la plus originale de l'ouvrage, car les livres qui traitent de l'industrie de l'érable négligent cette dimension propre à la culture populaire. À ce titre, l'approche ethnographique se distingue tout particulièrement dans cet ouvrage.

L'auteur ajoute à cette visite à la sucrerie une halte du côté des souvenirs et de ce qu'il est convenu d'appeler « le bon temps ». On y découvre la place de l'art populaire dans l'histoire culturelle du sucre d'érable. On peut y voir les différentes formes et les motifs que prennent les moules à sucre. L'auteur rappelle que « les pains de sucre, donnés en cadeau ou vendus, annoncent la sortie de l'hiver et le retour de la végétation, tant par le sucre, produit de la sève printanière, que par les images de la végétation inscrites sur le produit.» 
Les enquêtes ethnographiques réalisées par Dupont permettent finalement de dresser la liste du vocabulaire propre au temps des sucres dans la culture populaire. Ces termes et ces expressions révèlent la richesse et l'originalité de la langue populaire tout en démontrant comment cette activité s'est enracinée dans la culture québécoise.

Bien que cet ouvrage s'inspire des travaux menés par l'auteur, il y a plus de trente ans, il explore de nouveaux angles de cette tradition. À la lecture de ce livre, on sent bien que l'auteur ne tombe pas dans l'apologie. Il montre bien qu'il ne s'agit pas d'un produit unique au Québec, mais que l'exploitation du sucre d'érable a donné lieu ici à une culture qui se distingue par la langue, les coutumes et les pratiques culturelles originales. En ce sens, l'ouvrage de Dupont révèle que l'approche ethnographique permet de rendre compte du rapport que les Québécois entretiennent entre environnement et culture.

YVES BERGERON

Musée de la civilisation, Québec 